\title{
Debt Matters: The Firm's Optimization Problem With Financial Distress
}

Scott M. Gilpatric, (E-mail: scott@econ.tamu.edu), Texas A\&M University Richard V. Butler, (E-mail: rbutler@trinity.edu), Trinity University

\begin{abstract}
We argue that firms in financial distress face real costs associated with financial restructuring, in addition to the agency costs identified elsewhere in the literature. Distress costs arise from the presence of debt in the firm's financial structure. Because firms facing uncertain demand will act to minimize expected distress costs even when not near the point of defaulting on debts, the prospect of facing distress costs has implications for the optimization problem of every firm. Our model shows that distress costs have a nonlinear effect on the value function of the firm. This effect may make the firm risk averse or risk seeking, depending on the magnitude of expected distress costs, with very different implications for its output decisions. Our results bridge a gap between the emphasis of economists on risk aversion induced by financial distress and the view of legal scholars that financial distress induces risk-seeking behavior.
\end{abstract}

\section{Introduction}

Financial distress has many names. In economic theory we speak of "the shutdown decision," to be taken when a firm's anticipated revenues are less than its avoidable costs of production. In accounting and finance, a firm is said to be "insolvent" when its financial resources are inadequate to meet its obligations. Finally, there is the legal institution of bankruptcy, a collective mechanism for determining the future of troubled firms, many of which are not insolvent and may not face imminent shutdown within the bankruptcy forum. It is customary and seemingly reasonable to think of financial distress as a matter of concern mainly to distressed firms, their customers and suppliers. However, economists have recently come to realize that financial distress has economy-wide implications of some consequence (see, for example, Greenwald and Stiglitz (1993)).

In this paper we argue that the possibility of distress impacts many more firms than those conventionally thought of as troubled. The reason is simple: distress has costs that can appear before the firm is in serious trouble the agency costs of managers' inefficient pursuit of their own self-interests in the shadow of bankruptcy (which are emphasized by Greenwald and Stiglitz), and the real resource costs of operating in distress and resolving the firm's problems. A rational firm will act to reduce its exposure to these costs even when actual distress is not imminent.

In the rest of this paper, we develop a model showing how the costs of financial distress enter firms' optimization calculus and what the consequences are for the firm's decisions. The mechanism by which this works is unusual because the costs of distress are peculiar costs. They are peculiar because they can appear as the costs of new inputs (such as the costs of hiring bankruptcy lawyers), as increases in the costs of "ordinary" inputs (as when the cost of capital increases and trade creditors demand cash in advance from a struggling business), or as decreases in demand (as when travelers are reluctant to book flights on a distressed airline). They are also peculiar because they depend not on output but on profitability, and because they can affect future profitability long after the distress has passed. ${ }^{1}$ For these reasons, expected distress costs influence the optimization problem for both solvent and insolvent businesses, though the extent to which a firm's behavior will be influenced by distress costs will depend greatly on

Readers with comments or questions are encouraged to contact the authors via email. 
the financial position of the firm. Since these costs loom larger in the firm's value function as insolvency approaches, they affect the optimization problem of the firm disproportionately in the neighborhood of insolvency.

\section{Previous Research}

The conventional economists' model of profit maximization, which continues to serve us well seventy years after Jacob Viner first formalized it, contains an explicit analysis of the possibility that a firm's best choice will be to shut down--that is, that the firm will produce an output of zero over some particular run. One of the most significant implications of the model is that a firm will shut down only when the avoidable (i.e., neither fixed nor sunk) costs of producing a positive output exceed its expected revenues. In the long run, over which all costs are assumed to be avoidable, this implies that the firm will shut down if it expects to make negative profits. However, over any run in which some costs are fixed and unavoidable the model predicts that the firm may continue to produce a positive output though it is operating at a loss, because to shut down would only serve to increase losses in cases where revenues generated by sale of the output exceed avoidable costs. Put differently, all the options the firm faces lead to expected losses, but the expected loss is greater if the firm shuts down than if it produces.

But how long can a firm continue to operate at a loss? The model does not address this question. It implies that a firm will continue to operate at a loss indefinitely so long as the losses result from unavoidable costs or bad luck. No real firm could do this. If a firm has debt in its capital structure (which essentially all firms do, at least in the limited sense of trade credit), it must meet its flow of debt obligations from current revenues and liquid assets. If it fails to do so, its creditors have the right to take action against it. When a firm reaches this point, it is clearly in financial distress, and it will incur costs uniquely associated with resolving the claims of creditors to whom obligations have not been met. In effect, then, the standard model of profit maximizing firm behavior implicitly assumes that firms are constructed with only equity in their capital structure, or at least that they have a limitless "equity cushion" that shields them from creditor action. ${ }^{2}$

There are a few economic models that treat distress explicitly, though not in the way our model does. Greenwald and Stiglitz (1993) have developed a macroeconomic model of business cycles that incorporates the assumption that managers are personally averse to financial distress or bankruptcy ${ }^{3}$. Since informational failures make it difficult to determine if distress is the result of bad luck or bad management, they argue, managers believe that they will be stigmatized if the firm they manage suffers. For this reason, managers of firms in trouble will inefficiently favor liquid assets such as cash to buffer the firm from financial distress and will otherwise act in an excessively conservative manner. Thus, they argue, financial distress may not be costly for the firm per se, but the fact that managers perceive it as costly for themselves leads firms to behave risk-aversely. In particular, firms will produce less than the optimal output when financial distress looms.

Milne and Robertson (1996) advance an argument somewhat similar to that of Greenwald and Stiglitz. They assume an exogenous threat of liquidation if cash in hand falls below a specified level (representing credit market imperfections) and that the firm maximizes shareholder value defined as the value of the stream of dividend payments. The threat of liquidation in this model influences firm behavior even when well away from the liquidation threshold by inducing risk aversion. Risk aversion is a decreasing function of cash held internally by the firm, so it is most risk averse close to liquidation. They also show that output decisions will be dependent on the degree of risk aversion, and thus output is an increasing function of cash in hand.

These two models share the conclusion that the prospect of financial distress or liquidation induces riskaverse behavior in firms even when they are not facing liquidation or are otherwise obviously in distress. ${ }^{4}$ Many legal scholars, on the other hand, have discussed what is sometimes referred to as the "eve-of-bankruptcy" conflict. ${ }^{5}$ They note that when a firm nears default on its debts the interests of managers and shareholders diverge from those of creditors. The residual claimants may wish to take large risks to stave off default because they will receive the gains if the risk pays off, but they don't face the full downside cost since they already expect to lose their interest in the firm if it is liquidated. On this view, if default or liquidation are close a firm will likely be risk-seeking rather than risk-averse. These issues are discussed by Jackson and Scott (1989) and Daigle and Maloney (1994), who de- 
scribe various ways in which managers (acting in the interest of shareholders) may act contrary to the interests of other claimants when default is near, including their incentive to choose projects whose return has higher variance than those claimants would choose.

Our results suggest that the economists and the lawyers may both be correct because they are focused on opposite sides of the same coin. Our model shows that, depending on the financial position of a firm, distress costs can readily create areas of both concavity and convexity in the firm's value function, which correspond to risk-averse and risk-seeking behavior. We show that debt matters in analyzing the firm's optimization process - two firms, identical but for their level of debt, might behave differently even when not in financial distress because the more highly leveraged firm has higher expected distress costs. Our model demonstrates that the firm's propensity to seek risk will be influenced by expected distress costs even if it is assumed that decision-makers have risk-neutral preferences.

\section{Assumptions of the Model}

We develop below a model that systematically explains how financial position and the possibility of costly financial distress will affect the optimal behavior of a firm. The uniqueness of our approach is that it treats one area of potential costs--those arising from financial distress--outside the profit function. We do so because these costs are unique--they are a function of the profitability of the firm rather than being directly dependent on output or exogenously fixed. ${ }^{6}$ This approach allows us to isolate the effect of capital structure on the firm's decision making, facilitates analyzing the marginal effect of additional debt on the firm, and helps demonstrate how value-maximizing firm behavior may be very similar to risk averse or risk seeking utility maximization (with the firm's financial position determining its attitude toward risk) even though we assume risk neutrality on the part of decision makers.

The value function in our model plays a role analogous to that of the utility function in the theory of consumer utility maximization under uncertainty. A critical role of the utility function in analyzing behavior under uncertainty is that it takes into account the fact that the value to the consumer of losses and gains is not a linear function--if it were we could simply model the consumer as maximizing his monetary return over alternative investments. Likewise, in our model profits will not have a linear impact on the value of firms. Kahneman and Tversky (1979) have noted that losses or gains to a consumer which would precipitate a major event, such as a loss that necessitated selling one's home, can readily produce concave or convex regions to the consumer's utility function. Whereas Kahneman and Tversky indicate that these types of convexities/concavities are probably minor blips on the consumer's utility function, we believe that financial distress may often be a significant source of non-linearity in the value function of a firm. ${ }^{7}$

Note that when we speak of the value of the firm we refer to its value to all classes of current creditors (claimants) rather than just equity. ${ }^{8}$ We do this for two reasons: first, maximizing this broad measure of a firm's value, its full social value rather than that which accrues only to the residual claimants (shareholders), represents socially optimal firm behavior. Put differently, profits contribute to the value of the firm to which all claimants look to meet their claims--and equity holders are simply one class of claimants. It is conventional to portray the firm's agents as maximizing shareholder equity; if the result is inconsistent with maximizing the value of the firm to all claimants, this is an agency problem (though a very important one, and we will address it later). Second, since shareholders are limited liability residual claimants, the equity value of the firm reaches a lower bound at zero long before the value of the firm to all claimants reaches zero. At this point the equity value function will therefore be kinked and non-differentiable. Since our primary interest is in the firm's behavior in the neighborhood of this insolvency point (where equity is wiped out, and where the firm may default on its debts), this kink presents a significant practical obstacle that we will sidestep in our initial treatment of the problem. ${ }^{9}$ Later we will examine how assuming instead that the firm maximizes equity changes the optimization problem.

We assume that the firm's capital structure (in particular, its level of debt) is exogenously determined. Clearly this is not entirely realistic: firms optimize in their manner of raising capital as in other decisions, and the impact of debt on potential distress costs is certainly a factor in capital structure decisions. However, this is but one of a great many factors that impact the optimal capital structure of firms, ranging from tax treatment and relative 
transaction costs of raising capital via alternative instruments to the nature of a firm's assets and the volatility of its product markets. Seen in this context, treating capital structure as exogenous is a reasonable simplifying assumption. This assumption may seem more palatable if one thinks of capital structure as a long run decision made with full knowledge of the long run costs and benefits. From this perspective, the firm's capital structure was at least initially optimal. Once capital structure decisions have been made, the firm operates within the incentive framework created in part by the capital structure that was chosen. The incentive effects would have been understood at the time that capital structure decisions were made, and are fixed for some time thereafter. Though we do not attempt to model the capital optimization process, we do believe this model helps elucidate why different firms and different industries may be characterized by very different capital structures, a topic we will discuss later in the paper.

\section{The Model}

We examine the optimization problem for a firm in a multi-period, discrete time setting where it seeks to maximize the present value of profits from the current period onward:

$V(\pi)=\sum_{t=0}^{\infty} \pi_{t} \delta^{t}$ (where $\delta$ is the discounting parameter)

Normally we assume a firm will produce the optimal output in each period, which implies that it will not permanently shut down unless doing so maximizes its present value. If we assume that the firm's future cannot be jeopardized by present period events (the firm will operate in future periods so long as the expected value of doing so is positive, regardless of any disaster that befalls it presently) the value of the firm as a function of profits in the current period $(\mathrm{t}=0)$ is simply:

$V\left(\pi_{0}\right)=\pi_{0} \delta^{0}+\alpha$

In this expression $\alpha$ represents the present value at $\mathrm{t}=0$ of profits from all future periods; that is, $\alpha=\sum_{t=1}^{\infty} \pi_{t} \delta^{t}$.

Economists often think of $\alpha$ as simply a constant, or uncertain but independent of profits at time $t=0$. In that case it is apparent that the value of the firm is a linear function of current profit, and therefore the implications of the multi-period optimization problem for the actions of the firm in the present are identical to those of single period profit maximization. Alternatively, in some models there is interaction between profits in different periods due to the presence of a state variable in the firm's production function (typically capital). In this case the firm's problem is to choose the optimal dynamic path. Since we are not exploring dynamic optimization in this sense we will not include state variable effects in our model. Instead we assume that the only interaction between current and future profits is through the effect of financial distress on future profits.

In our model the term $\alpha$ represents the present value of future profits. It is also the upper bound on the firm's potential distress costs, since it is optimal to shut down if the cost of resolving the firm's distress exceeds its expected future profits. But this has an important implication: the firm's financial structure affects the determination of whether shutdown is the best course of action. Since restructuring is costly, it may be optimal for a firm with large debts that must be restructured in order to survive to shut down whereas, if the firm were structured with less debt and therefore faced lower financial distress costs, it would not shut down. One can think of $\alpha$ as the value of completely avoiding distress, since distress implies that there is some cost of resolving the firm's problems in order to continue to produce in the future. A firm facing financial distress has a choice: incur the costs of financial restructuring, or simply shut down and liquidate and thus avoid restructuring costs but forfeit future profits. If the costs of restructuring exceed expected future profits it will shut down. Financial distress is costly in both cases; either the firm incurs restructuring costs that would have been avoided if the firm were financially stronger, or it liquidates and loses all future profits. 
To complete the picture, note that the liquidation value of the firm is an opportunity cost of operating the firm and therefore the present value of the firm's profits over all periods is net of this liquidation value. However, liquidation value certainly should be included as a component of the total present value of the firm to its stakeholders. ${ }^{10}$ For example, if the liquidation value of a firm, " $L$ ", is $\$ 100,000$ and $\sum_{t=0}^{\infty} \pi_{t} \delta^{t}=\$ 10,000$, then the present value of the firm is $\$ 110,000$, not $\$ 10,000$.

We begin our analysis of the impact of financial distress and possible shutdown with a very simple example. Assume that a firm will default on its debt if it does not make a positive profit in the present period (we will dispense with the subscript for the period $t=0$ ), and if it defaults the cost of resolving the distress will be so great that the firm will do better to shut down, losing the entire value $\alpha$ (one can think of this as a case where credit law renders it extremely costly to restructure debts) ${ }^{11}$. In this very stylized case the firm's value as function of present period profit will be:

$$
\begin{aligned}
& V(\pi)=L+\pi+\alpha \text { if } \pi \geq 0 \\
& V(\pi)=L+\pi \text { if } \pi<0
\end{aligned}
$$

Notice that the value function is linear but discontinuous at the point of zero profit. This poses a problem since we would find a continuous and differentiable function much more tractable. But in fact this discontinuity isn't a very good representation of reality. Even if we assume the firm knows precisely the amount of losses it can suffer while avoiding default on its debts, it does not follow that any level of profit above this point yields zero distress cost. It may be that a firm will be able to avoid default, but only by liquidating resources which otherwise would have supported valuable investments in future productivity, thereby reducing future profits. The reputation or brand value of a firm may be damaged if customers see it as financially troubled, suppliers may be reluctant to extend normal trade credit and its cost of capital may rise as creditors become aware that loans to the firm are at greater risk, and it may find recruiting employees more costly due to increased skepticism about the future of the company. ${ }^{12}$ These and many other distress costs are likely to be inversely related to profitability and will begin to occur long before default is reached. Indeed, one would expect that they would grow at an increasing rate as profit declines toward the default point. On the other hand, default itself often does not create such large costs that it becomes optimal to shut down and liquidate the firm. In many cases the firm will be able to renegotiate or reschedule its debts with the agreement of creditors who see that liquidation will not serve their interests (though such a process will be costly). Those firms which cannot attain the agreement of their creditors for a restructuring may also be able to utilize Chapter 11 bankruptcy to achieve a reorganization which preserves much of the going concern value of the firm, though this will likely be still more costly. It is commonly the case that, though resolving financial distress is costly, it is better than the liquidation alternative.

Overall, then, it is reasonable to assume that the difficulty and cost of resolving distress will be a monotonically decreasing (but nonlinear) function of current profits.

Accordingly, the tripwire default and shutdown assumption is not very realistic. A better model would incorporate the marginal cost of financial distress to the firm in a smooth and continuous manner. At one end truly disastrous profits may render liquidation the best alternative, or require very costly resolution. At the other end a firm with healthy profits would experience very little distress cost; in this case we can think of distress costs approaching zero. Between these extremes distress costs decline smoothly as profits grow.

\section{Distress Costs in the Value Function}

Let $\mathrm{F}(\pi)$ be the function mapping any present period profit into the proportion of future profits $\alpha$ that remain available to the firm net of distress costs-so $F(\pi)$ has values on the interval $(0,1)$. One can readily think of this function as analogous to a cumulative distribution function of a random variable, but note that we are not assuming 
any randomness of distress costs. ${ }^{13}$ We denote the first derivative of this function $f(\pi)$, which thus represents the marginal increase in future profits obtainable given present $\pi$. We assume that $F(\pi)$ is a unimodal distribution and that $\gamma$ represents the mode, which we will assume is the default point for the firm. ${ }^{14}$ Thus $\mathrm{f}^{\prime}(\pi)>0$ for $\pi<\gamma$, $\mathrm{f}^{\prime}(\pi)<0$ for $\pi>\gamma$ and $\mathrm{f}^{\prime}(\pi)=0$ for $\pi=\gamma$. The distress cost function is then:

$$
D=\alpha(1-F(\pi))
$$

the proportion of $\alpha$ that is lost to distress. This generates values that are a high proportion of $\alpha$ for low levels of profit and a low proportion of $\alpha$ for high levels of profit.

We now incorporate this distress cost function into the value maximization equation, where the value of the firm is the sum of its liquidation value (L) plus present profits $\square(\pi) \square$ and future profits $\square(\alpha) \square$ less the costs of distress:

$V(\pi)=L+\pi+\alpha-\alpha(1-F(\pi))$

We can rewrite the equation as:

$V(\pi)=L+\pi+\alpha(F(\pi))$.

Now we turn to examining the behavior of the value-maximizing firm under uncertainty in a world where financial distress is possible. Equation (7) has the following first and second derivatives:

$V^{\prime}(\pi)=1+\alpha(f(\pi))$
$V^{\prime \prime}(\pi)=\alpha f^{\prime}(\pi)$.

It is clear that:

$$
\begin{aligned}
& V^{\prime}(\pi)>0 \text { for all } \pi \\
& V^{\prime \prime}(\pi)>0 \text { if } \pi<\gamma \\
& V^{\prime \prime}(\pi)<0 \text { if } \pi>\gamma \\
& V^{\prime \prime}(\pi)=0 \text { if } \pi=\gamma
\end{aligned}
$$

The first derivative indicates that the value of the firm will, of course, always be an increasing function of current profits. The second derivative indicates that the value of the firm will increase at an increasing rate to the left of the default point $\gamma$ and increase at a decreasing rate to the right of this point. That is, if we start far to the left on the profit axis, where the firm's demise is nearly certain, and move along this axis to the right as profits increase, we see the value of the firm increasing more than linearly in $\pi$ because each additional dollar of profit avoids an increasing amount of expected distress costs until we reach $\gamma$ At this point the marginal benefit of avoided distress peaks, so as we move further along the profit line the value of the firm increases at a decreasing rate because the effect of reducing distress costs is gradually fading away as these costs approach zero.

Therefore, debt alters the value function of the firm so that it is "S-shaped": convex to the left of $\gamma$ and concave to the right of $\gamma$. (Figure 1 illustrates the S-shape of the value function in the case of normally distributed distress costs.) The value function acts on the incentives for the firm much as a utility function does when one assumes the owner of a firm maximizes the utility of profits, with the convex portion clearly analogous to risk seeking expected utility maximization and the concave portion analogous to risk averse preferences. ${ }^{15}$ 


\section{The Optimization Problem with the S-Shaped Value Function}

A substantial literature exists describing the behavior of a firm facing uncertain demand and the important role of a non-linear value (or utility) function under such circumstances. Since the incorporation of financial distress costs into the model of the firm generates an S-shaped value function we can apply the results of this literature directly to analyze how financial distress impacts firm behavior. The simplest model is that of the competitive firm for which demand uncertainty can be represented by a stochastic price (Sandmo, 1971). This model is sufficient to demonstrate the most important implications of distress costs on firm behavior and is very intuitively appealing so we discuss it at some length. However, we recognize that, though the competitive model is illustrative, distress costs are not strictly consistent with perfect competition, so we discuss non-competitive models as well.

The following exposition of expected value maximization closely follows Sandmo's treatment of expected utility maximization with the difference that the value function, unlike the utility function, is not concave throughout. We describe the firm's cost function (excluding distress costs) as:

$$
H(x)=C(x)+B
$$

where $x$ is output, $C(x)$ is the variable cost function, and $B$ is fixed cost (which includes the cost of debt payments). We assume (conventionally) that

$\mathrm{C}(0)=0, \mathrm{C}^{\prime}(\mathrm{x})>0, \mathrm{C}^{\prime}{ }^{\prime}(\mathrm{x})>0$

Thus the firm's profit function is:

$$
\pi(x)=p x-C(x)-B
$$

where $p$ is the price of the firm's output which is assumed to be a random variable with density function $g(p)$ and $E[p]=\rho$.

The expected value of profits can now be written as:

$$
E[V(p x-C(x)-B)]
$$

The necessary and sufficient conditions for a maximum are $^{16}$ :

$$
\begin{aligned}
& E\left[V^{\prime}(\pi)\left(p-C^{\prime}(x)\right)\right]=0 \\
& E\left[V^{\prime \prime}(\pi)\left(p-C^{\prime}(x)\right)^{2}-V^{\prime}(\pi) C^{\prime \prime}(x)\right]<0
\end{aligned}
$$

Sandmo (1971) demonstrated the important result that a risk averse expected-utility-maximizing firm will produce less under price uncertainty than the certainty equivalent or the profit maximizing output. That is, the optimal output will be smaller if the price is uncertain with an expected value of $\rho$ than if the price is certain to be $\rho$ The certainty/profit maximizing output is, importantly for our purposes here, also the optimal output for an all-equity firm which bears no risk of financial distress and for which the expected value function is therefore linear. It should be evident that where $V^{\prime \prime}(\pi)<0$ the expected-value-maximizing firm will optimize similarly to the risk averse expected utility maximizer and will produce less than the profit maximizing output. Conversely, where $V$ " $(\pi)>0$ the expected-value-maximizing firm will have an optimal output greater than the profit maximizing output. We show the latter case in the appendix since it differs from that addressed by Sandmo, though the steps are parallel. ${ }^{17}$

Where the expected value function is convex $(E[\pi]<\gamma$ the firm's optimal output is attained where marginal 
cost is greater than the expected price of the competitive output, which implies that this optimum is greater than the profit maximizing output. Intuitively, a firm in this region of the value function faces grim prospects (a high expected distress cost) and gambles that the realized price in the output market will be higher than expected and thus enable it to avoid distress costs. The other case, where the expected value function is concave, of course results in the opposite implication that optimal output will be found where marginal cost is less than the expected price. In this region the firm lowers expected distress costs by reducing output.

If we drop the assumption of perfect competition with stochastic price in favor of the more general assumption that the firm faces downward sloping uncertain demand of the form $p=f(q, u)$, where $u$ is a random variable, the implications of the S-shaped value function generated by distress costs are not substantially altered. The "principle of increasing uncertainty" states that as total expected revenue increases the dispersion of total revenue increases as well. Leland (1972) has shown that so long as this principle holds, a risk-averse quantity-setting firm will produce less than the certainty or profit-maximizing output while a risk-seeking firm will produce more. In fact, the competitive model described above is simply a special case of this since the principle of increasing uncertainty always holds under perfect competition. ${ }^{18}$

\section{The Value Function and Risk Preferences}

Unlike the utility function, which is simply assumed to be concave, the shape of the value function is not obvious: it depends on expected profits, which in turn depend on output. ${ }^{19}$ It is true that different possible outputs that would generate different expected profits could lead to opposing attitudes toward risk if they are on opposite sides of the inflection point $\gamma$. Note, however, that if a firm produces more or less than the profit maximizing output it will, by definition, reduce expected profits. This means that if the profit maximizing output falls to the left of $\gamma$ and the firm consequently increases output as a means of risk seeking, expected profit will move further to the left of zand thus the firm will clearly remain risk seeking. But if the expected profit maximizing output falls just to the right of $\gamma$ then the firm might reduce output as a means of risk aversion. This would reduce expected profit, possibly to the inflection point $\gamma$ but the firm would never have incentive to reduce output further because at $\gamma$ we see that $V$ ' $(\eta)=0$, the firm is risk neutral. Thus, the qualitative risk attitude will be determined by the value of expected profits at the profit maximizing output, and a firm will not cross over from risk aversion to risk seeking (though an exogenous shock effecting one or more of the parameters in the value function could, of course, lead to an change in the firm's attitude toward risk).

The default point $\gamma$ becomes the inflection point of the value function and represents the profit level at which the marginal impact of profits on distress costs peaks, but note that default is a marginal step in our model, not a cliff beyond which the firm faces dissolution. One might naturally assume that default would occur at or near zero profits, but this is not necessarily the case. The value of $\gamma$ will depend on the length of the run involved, the amount of debt owed by the firm in this time period, and its ability to raise new equity capital. In fact, $\gamma$ will never be positive and will be negative for most firms over most periods. This is because, though a firm may not generate revenue in excess of all costs over some period, it is likely in many instances to be able to make up the difference by liquidating assets or raising new capital. Indeed, this is exactly what the standard profit-maximizing model supposes when we say that a firm will continue to produce a positive output though it makes a loss in the short run. Because a firm cannot make a loss over an arbitrarily long period without facing distress, the value of $\gamma$ must approach zero as the period being analyzed approaches infinity because the resources of a firm and its ability to draw equity investment to meet debt claims are finite. Also note that a firm that makes a loss in one period will face a higher $\gamma$ in the next period, ceteris paribus, because it will have liquidated some of its assets leaving it with fewer reserves (though an injection of additional equity capital could offset this).

We have used a very general model of the distribution of distress costs, F $(\pi)$, because the shape of this function will vary greatly with the capital structure of the firm. It is evident that the more highly leveraged is the firm the more profit will be necessary to cover the cost of debt payments and therefore the higher will be the default point $\gamma$. But capital structure (in conjunction with credit law and legal institutions) will alter the distribution of distress costs in other ways as well. For instance a firm with "hair trigger" debt contracts that precipitate default the moment 
payments are missed would likely face distress costs concentrated closer to the default point than if contracts allow some rescheduling of payments if a penalty fee is paid. In this way debt contracts impact the variance of the distribution. ${ }^{20}$ Capital structure, as well as the nature of the firm's business, will also affect how the distribution is skewed. Some firms may face high distress costs long before defaulting due to such things as reluctant customers or worried capital markets, while others will face only minimal distress costs unless they actually default. Capital structure in conjunction with the other factors mentioned influences at least three moments of the distribution of distress costs.

\section{The effect of fixed costs}

Another important result from the literature on firms under uncertainty is that decreasing absolute risk aversion is a sufficient condition to prove that optimum output will be a decreasing function of fixed costs for a risk averse expected utility maximizer; that is, the partial derivative of output $(x)$ with respect to fixed costs $(B)$ is negative. Correspondingly, in our model, where the value function exhibits decreasing absolute risk aversion this will be sufficient to prove that the optimal output for the expected value maximizing firm will be a decreasing function of fixed costs, which include debt payments. The converse is also true: where the expected value function exhibits the characteristics of increasing absolute risk aversion the optimum output will be an increasing function of fixed costs. These results depend on the principle of increasing uncertainty, but apply to all quantity-setting firms (Leland, 1972).

The absolute risk aversion function is

$R_{A}(\pi)=\frac{-V^{\prime \prime}(\pi)}{V^{\prime}(\pi)}$

For any value function based on the assumptions we have outlined such that distress costs are a twice continuously differentiable function of profit with a single inflection point we can make a fairly powerful statement about the risk aversion function: it will be zero (indicating risk-neutrality) at the inflection point, and will approach zero in the tails as profits become arbitrarily large or small as $V^{\prime \prime}(\pi)$ approaches zero. Furthermore, the risk aversion index will have a positive maximum (the point of maximum risk aversion) to the right of the inflection point and a negative minimum (the point of maximum risk seeking) to its left. (Figure 2 illustrates the absolute risk aversion function for a firm with normally distributed distress costs.) The function will exhibit decreasing risk aversion both to the left of the minimum (maximum risk seeking) and to the right of the maximum. It will, of course, exhibit increasing risk aversion between the minimum and maximum.

The most important implication is that, since we expect that most financially healthy firms will be operating to the right of the point of maximum risk aversion, they will exhibit decreasing absolute risk aversion as a function of profit. Thus an increase in a fixed cost, such as debt, will have the marginal effect of reducing the firm's output because it will reduce the profit associated with all potential outcomes. In other words, an increase in fixed costs causes the firm to be more risk averse because it reduces expected profit and makes financial distress more likely, and one manner of reducing risk is to reduce output. On the other hand, a firm that is to the left of the risk aversion maximum (though it still may be to the right of the default point) will exhibit increasing risk aversion, and consequently an increase in debt or other fixed costs will cause the firm to take greater risks including increasing output.

\section{The Equity Maximizing Firm}

So far we have been assuming a value-maximizing firm, one for which the management of the firm considers the interests of all existing claimants equally. But suppose instead we assume that the firm's decision maker is an agent only of shareholders, who have claims to shares of the residual equity value, and seeks to maximize only the equity value of the firm (the value of the firm net of existing debt), rather than the full value of the firm. We will denote this equity function as $W(\pi)$. Changing to equity maximization has only a level effect on the optimization problem (i.e., it does not alter the marginal effects of profits) and therefore would not change the implications for the firm's decisions except for a very important difference: equity reaches the lower bound of zero, where the function is 
kinked, long before the value of the firm reaches its zero boundary. Mathematically, for values of profit sufficient to produce positive equity the following relationships will hold:

$W^{\prime}(\pi)=V^{\prime}(\pi)$

$W^{\prime \prime}(\pi)=V^{\prime \prime}(\pi)$

But for profit levels that lead to zero equity the equations cease to be valid. Though we cannot differentiate the function at this point, we can conclude that this lower bound will make the equity-maximizing agent more risk seeking than if he were value maximizing. Any portion of the distribution of demand which is expected to lead to profits that will be sufficiently low as to completely wipe out equity will be completely discounted; only the upper portion of the distribution which provides some expected return to the equity maximizer will be relevant. Put another way, the equity holders of the firm will take greater risks (including choosing a higher output) because they do not bear the full downside costs of their decisions.

This is a manifestation of the agency problem known as the "eve-of-bankruptcy conflict". It has been widely recognized by bankruptcy scholars that the incentives facing shareholders and managers may diverge from those of other creditors (and produce socially non-optimal behavior) when insolvency threatens. An equity-maximizing agent faces essentially the same incentives as a value maximizer so long as the firm is comfortably distant from the point of insolvency where equity will be wiped out, and will therefore optimize in all claimants' best interest. But the closer insolvency nears, the greater the divergence in the interests of shareholders versus debt claimants. This is the principal reason credit law typically limits the rights of debt holders so long as their contractual claims are met, but provides for swift action (e.g., foreclosure) if they are not--an indication insolvency may be at hand. ${ }^{21}$

\section{Implications for the Theory of the Firm}

Our model has yielded three striking conclusions about firm behavior: 1) Debt creates a non-linearity in the value function of a firm by adding the potential cost of financial distress, so that the firm will optimize as though it were risk averse or risk seeking, depending on where expected profit falls in its distress cost function. By contrast, an all-equity firm will not have this non-linearity in the value function. 2) This non-linearity in the value function will lead the firm to behave as if it is not risk neutral and therefore generally to produce an output that is not consistent with conventional analysis. Value maximizing behavior that incorporates the incentives created by debt is nevertheless economically efficient, though equity-maximizing behavior may differ significantly from the optimum if the firm faces a high probability of insolvency. 3) Fixed costs are likely to affect output and other decisions made by firms with debt, which therefore face the possibility of distress costs, because they alter the proclivity for risk. Debt is itself a critical fixed cost, and the level of debt owed by a firm will impact its output and other decisions involving risk. We have also seen how debt marginally impacts the risk attitude of the firm. Financial position plays an important role in determining the firm's attitude toward risk and consequently its output and investment decisions, particularly when these decisions involve some probability of distress.

Our results agree with earlier models, such as that of Milne and Robertson, in the respect that a firm's financial position will affect its attitude toward risk and optimal output. But there is an important difference. In those models risk aversion is typically monotonically increasing as the firm's financial position worsens, resulting in maximum risk aversion at the brink of liquidation. However, we have shown that when the firm faces a high probability of liquidation it is likely to be risk seeking rather than risk averse. In this respect our model is in agreement with the bankruptcy literature arguing that firms will take greater risks as liquidation nears in hopes of avoiding such an outcome.

These results imply that models of firm decision making which do not address the impact of the financial position of the firm will overlook some potentially important aspects of real-world business behavior. Ignoring the impact of debt and possible financial distress may not be troublesome for many applications since most firms at most moments in time may be far from imminent distress. However, such a model is at a significant disadvantage when one attempts to apply it to decisions surrounding default where the critical factors may be ignored by assuming the 
value function of profits to be linear. There are many other cases in which the value-maximizing model with distress costs would be a more appropriate choice. One example is the firm that faces highly variable demand or costs, which in turn may create a significant probability of distress even when the firm is apparently financially healthy. The more general value-maximizing model will also better explain very large investment decisions or behavior over relatively long runs since these cases will involve a significant prospect of financial distress. ${ }^{22}$

Our model clearly has macroeconomic implications as well. Greenwald and Stiglitz have shown that when firms act as if they are risk averse this can generate cyclical behavior and lead to economic shocks (such as price shocks) having persistent effects. Our model strengthens their argument by showing that risk-averse behavior among firms can readily result from very plausible assumptions about distress costs. Furthermore, we have extended the Greenwald and Stiglitz analysis by showing how firms' attitudes toward risk are influenced by their financial position, including the possibility that firms facing high expected distress costs will be risk seeking rather than risk averse $^{23}$. This complicates the analysis of the macroeconomic implications of an economic shock that worsens the financial position of many firms in the economy. But note that though some firms become more risk seeking while others may become more risk averse, it may be of greater significance to recognize that in either case distress costs rise. A negative shock will cause many firms to engage in costly restructuring while some marginal firms will shut down which would have survived in the absence of the shock. In this sense the initial shock is "amplified" by the costs of firms having to respond. (There are probably similar costs in the household sector as well).

Finally, while recognizing that a great many factors influence capital structure decisions, the analysis we have presented does have implications for the type of capital structure we would expect, ceteris paribus, certain types of firms to exhibit. The potential cost of financial distress will be greater for firms in industries where distress may quickly destroy demand or otherwise damage the firm's future, and for firms that face a high level of uncertainty in their product markets or costs. (No amount of curvature in the value function will cause a value maximizing firm to behave differently from a profit maximizing firm if it does not face stochastic demand or costs, and the greater the uncertainty, the greater the effect). Consequently our analysis suggests that firms with few tradable assets and for which $\alpha$ represents the bulk of the firm's value (e.g., an advertising agency or a software developer) and those facing highly variable or cyclical demand (such as construction contractors) would tend to raise less capital through debt than would asset-rich firms in industries with stable demand and costs. These factors make marginal increases in debt more costly than for firms that would suffer less from default or face lower probability of its occurrence due to more stable costs and revenues.

\section{Implications for Bankruptcy Policy}

Financial distress and bankruptcy motivated our new analysis of the firm's optimization problem, and our arguments have implications for bankruptcy policymaking. Our model supports two central tenets of bankruptcy scholarship. First, bankruptcy policy (by which we mean the manner in which financial distress is legally resolved) is relevant not just in determining which bankrupt firms survive and in what form: it also affects the decisions of many more firms when they contemplate actions that carry risk and may lead to distress. If bankruptcy policy succeeds in reducing distress costs by preserving going concern value, it will reduce the distortions that the prospect of distress creates for firms even when healthy. In terms of our model, more efficient resolution of financial distress will lower the distress costs corresponding to each level of profit and may shift the inflection point of the value function to the left, thereby reducing the magnitude of the distortion in the value function created by distress which would in turn reduce the degree of risk aversion and risk seeking which could occur. In this way society's bankruptcy institutions are likely to have a significant impact on the risk taking attitudes of all firms, as well as on capital structure decisions. Efficient bankruptcy forums may be critical to encouraging entrepreneurial risk taking in an economy; lower expected distress costs result in a lower cost of capital.

Bankruptcy scholars have often discussed the "eve-of-bankruptcy conflict," the idea that the owners of a firm have an incentive to take great risks with the firm's assets when insolvency looks imminent in the hope of avoiding this event. Our analysis places this behavior in a broader context. We see that this behavior is a manifestation of an ever-present incentive factor in the firm's decision making. Under circumstances where the firm faces little pros- 
pect of default, adding distress costs to the equation may have a minor impact, but when the firm is operating in a circumstance such that $\mathrm{E}[\pi]$ is to the left of the default point we would expect the impact to be very significant. We see that some risk seeking may in fact be optimal for maximizing the firm's value, but that the amount of additional risk sought is much greater when one assumes the agent is maximizing only equity rather than the full value of the firm -- there is indeed a "conflict" between the interests of a manager serving only equity and the general interests of all stakeholders in the firm. This also supports the idea, embodied in the 1978 Bankruptcy Code, that the bankruptcy forum should not be limited to insolvent firms. Since maximizing the value of the firm to all classes of claimants is a stated goal of bankruptcy policy, and equity interests will diverge from those of other claimants before insolvency occurs, it is rational that the forum be available to firms well in advance of the point of technical insolvency and that risky action immediately prior to a filing receive much greater scrutiny.

\section{Appendix}

\section{Proof that where $V^{\prime},(\pi)>0$ the optimal output will be greater than profit maximizing output:}

From the first order condition we have:

$$
E\left[V^{\prime}(\pi) p\right]=E\left[V^{\prime}(\pi) C^{\prime}(x)\right]
$$

By subtracting $E\left[V^{\prime}(\pi \rho]\right.$ from both sides of the equation we get:

$$
E\left[V^{\prime}(\pi)(p-\rho)\right]=E\left[V^{\prime}(\pi)\left(C^{\prime}(x)-\rho\right)\right]
$$

From the profit function we have $\pi=p x-C(x)-B$ and $E[\pi]=\rho x-C(x)-B$. Therefore we can write:

$$
\pi=E[\pi]+(p-\rho) x
$$

Because the expected value function is convex to the left of $\mu$, we know that in this region (where $E[\pi]<\mu$ ):

$$
V^{\prime}(\pi) \geq V^{\prime}(E[\pi]) \text { if } p \geq \rho \text { and } V^{\prime}(\pi) \leq V^{\prime}(E[\pi]) \text { if } p \leq \rho
$$

From this it follows that

$$
V^{\prime}(\pi)(p-\rho) \geq V^{\prime}(E[\pi])(p-\rho) \text { if } E[\pi]<\mu
$$

which holds for all $p$. We now take expectations of both sides, observing that $V^{\prime}(E[\pi])$ is not stochastic but is a particular number, which gives us:

$$
E\left[V^{\prime}(\pi)(p-\rho)\right] \geq V^{\prime}(E[\pi]) E[p-\rho]
$$

Notice that since the right hand side is zero $(E[p-\rho=0)$, the left hand side must be positive (the inequality is strict unless price is non-stochastic in which case $p=\rho$ and both sides of the expression are zero). This implies that the right hand side of (2) above must also be positive:

$$
E\left[V^{\prime}(\pi)(p-\rho)\right]=E\left[V^{\prime}(\pi)\left(C^{\prime}(x)-\rho\right)\right] \geq 0
$$

But, since $V^{\prime}(\pi)>0$ for all $\pi$, it must be true that:

$$
C^{\prime}(x) \geq \rho
$$


This inequality is strict if price is stochastic. If price is deterministic we see the conventional result that the firm optimizes where price equals marginal cost, but uncertainty together with the nonlinear value function lead to a strikingly different result.

\section{References}

1. Aghion, Philipp; Hart, Oliver; and Moore, John, "The Economics of Bankruptcy Reform," The Journal of Law, Economics, \&Organization 8 (1992), 523-545.

2. Black, Fischer and Scholes, Myron, "The Pricing of Options and Corporate Liabilities," The Journal of Political Economy 81 (May 1973), 637-654.

3. Daigle, Katherine H. and Maloney, Michael T., "Residual Claims in Bankruptcy: An Agency Theory of Explanation," Journal of Law and Economics 37 (April 1994), 157-192.

4. Friedman, Daniel, "The S-Shaped Value Function as a Constrained Optimum," American Economic Review 79 (December 1989), 1243-1248.

5. Greenwald, Bruce C. and Stiglitz, Joseph E., "Financial Market Imperfections and Business Cycles," The Quarterly Journal of Economics 108 (February 1993), 77-114.

6. $\quad$ Ireland, Norman J., "Product Diversity and Monopolistic Competition Under Uncertainty," Journal of Industrial Economics 33 (June 1985), 501-513.

7. Jackson, Thomas H. and Scott, Robert E., "Symposium on the Law and Economics of Bargaining: On the Nature of Bankruptcy: An Essay on Bankruptcy Sharing and the Creditors' Bargain," Virginia Law Review 75 (March 1989), 155-204.

8. Kahneman, Daniel and Tversky, Amos, "Prospect Theory: An Analysis of Decision Under Risk," American Economic Review 47 (March 1979), 263-292.

9. Leland, Hayne E., "Theory of the Firm Facing Uncertain Demand," American Economic Review 62 (June, 1972), 278-291.

10. Meckling, William H., "Financial Markets, Default and Bankruptcy: The Role of the State," Law and Contemporary Problems 91 (1977), 13-38.

11. Milne, Alistair and Robertson, Donald, "Firm Behavior under the Threat of Liquidation," Journal of Economic Dynamics and Control 20 (1996), 1427-1449.

12. Sandmo, Agnar, "On the Theory of the Competitive Firm under Price Uncertainty," American Economic Review 61 (March 1971), 65-73.

13. Stiglitz, Joseph E. and Weiss, Andrew, "Credit Rationing in Markets with Imperfect Information," The American Economic Review 71 (June 1981), 393-410.

14. Viner, Jacob, “Cost Curves and Supply Curves," Zeitschrift für Nationalökonomie 3 (1931), 23-46. 
Figure 1

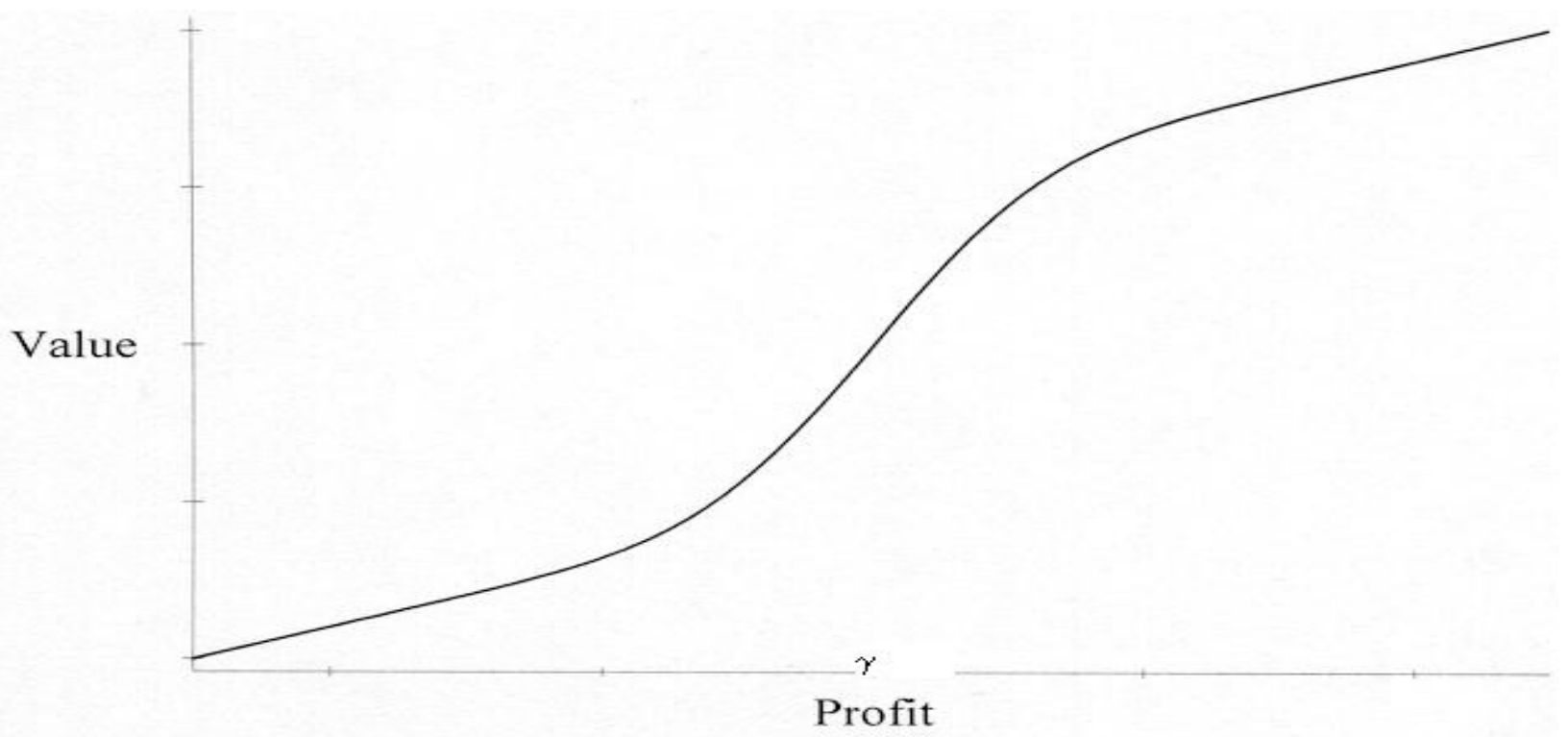

The S-Shaped Value Function

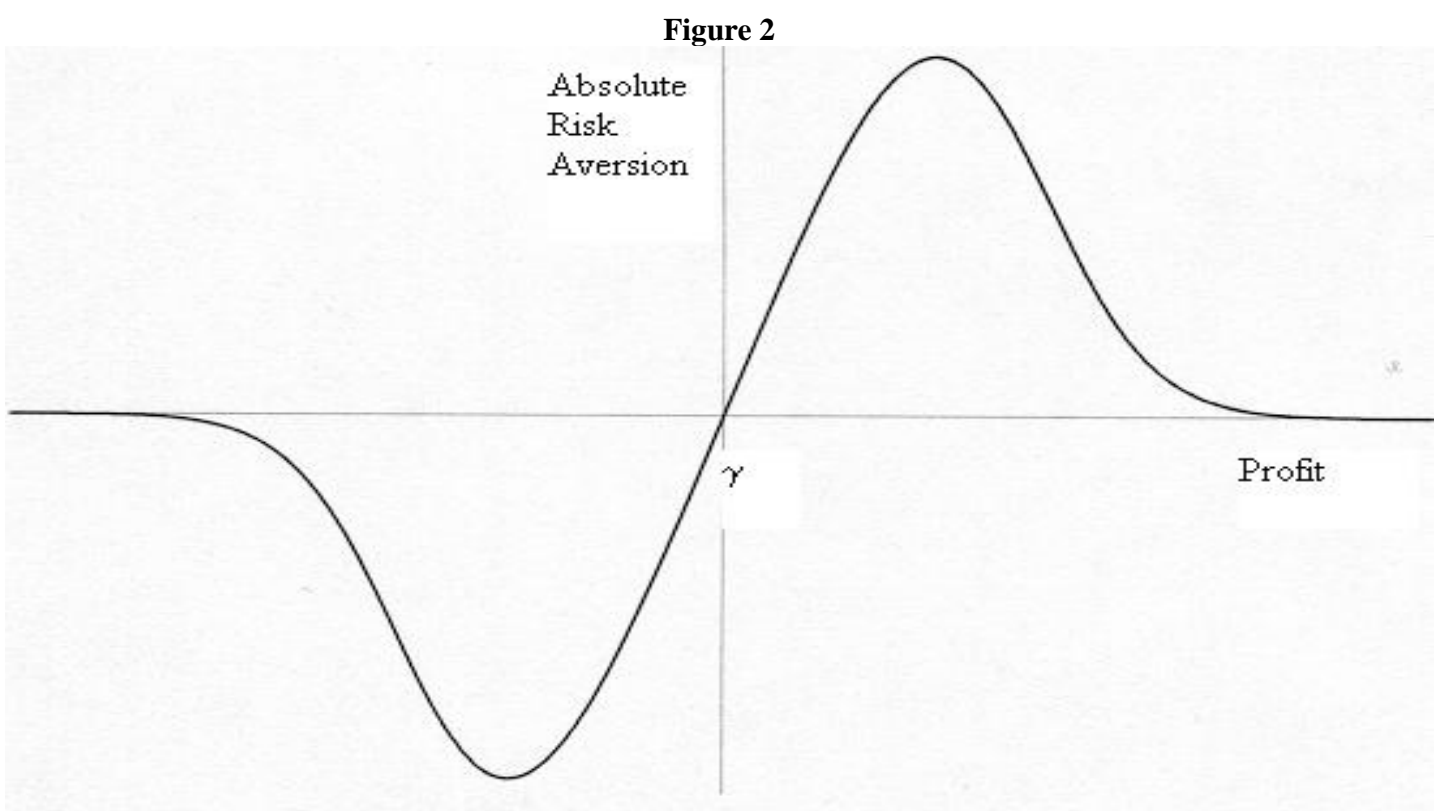

The Risk Aversion Function 


\section{Endnotes}

We thank William Neilson, John Huston, Barry Hirsch and seminar participants at Texas A\&M University for their comments and advice.

1 For example, both customers and suppliers may for some time deal more warily with a once-distressed firm even though its current financial condition is sound - "once burned, twice shy."

2 Note that since debts are unavoidable contractual costs, and the long run is conventionally defined as a period over which all costs are variable (avoidable), decisions taken over any period in which debts are owed are, by definition, short run decisions. One of the functions of the bankruptcy forum is to allow a firm to renegotiate, or abrogate, debt contracts. Thus bankruptcy makes some costs avoidable that were unavoidable outside this forum.

3 While Greenwald \& Stiglitz motivate their model by focusing on managerial aversion to the possibility of bankruptcy (see p. 79 and footnote 5), they also address briefly how reorganization costs could be incorporated into that model (see footnote 12).

4 Greenwald and Stiglitz do note in passing the possibility that firms could be risk-seeking rather than risk-averse when facing bankruptcy (see footnote 16), but they do not develop the implications of that case.

5 See, for example, Jackson and Scott (1989), Daigle and Maloney (1994), and Meckling (1977).

6 Since distress is the result of inadequate profits, even the distress costs that manifest themselves as changes in demand or input prices are best represented this way. The reason is that the magnitude of the change in the cost of inputs or demand is not exogenously determined but instead depends on the firm's profitability.

7 The assets of an individual, especially her future earnings potential, are significantly protected from creditors under nearly all modern legal systems (e.g., we no longer imprison people for failure to pay their debts), whereas the assets of a firm may be liquidated entirely and all expected future profits, if such exist, destroyed.

8 For further discussion of why it is appropriate to measure the value of the firm as the sum of debt and equity see Black and Scholes (1973) at p. 650.

9 The full value of the firm to its creditors is bounded below at zero as well, but this point corresponds to a firm which has been completely dissolved (has no assets of any kind) so it is of little importance. In other words, a firm with any debt would be insolvent and distressed long before its value reached this lower bound.

${ }^{10}$ Note that the firm could not increase its value by simply borrowing money and buying liquid assets because the increase in liquidation value would be offset by a fall in the present value of expected future profits of equal or greater magnitude because the firm would face the cost of additional debt payments in the future.

${ }^{11}$ Though this example may seem rather contrived, it is in fact very similar to the assumptions made by other economists. Milne and Robertson (1996), for example, assume that if profits fall below a "tripwire" point the firm will be dissolved.

${ }^{12}$ A firm may have some costs that actually fall as profits fall and distress approaches. In particular, though we note above that distress may require that the firm pay a compensating wage differential due to employment uncertainty, distress may in other cases reduce labor costs. Consider heavily unionized settings, for example, where demands for wage increases are tied to firm profitability. Nevertheless, financial distress is certain to be a costly event for a firm on the whole. 
${ }^{13}$ In our model only demand is assumed to be uncertain. However, one might readily conceive that distress costs (or other costs) might be uncertain as well, but adding these assumptions complicates the model without changing its implications.

${ }^{14}$ We assume the default point is where the marginal distress cost associated with a decrease in profit peaks, which is why it corresponds to the mode of the distress cost distribution. If the default point were not associated with the mode of the distribution this would not fundamentally change the analysis.

15 Interestingly, some empirical evidence suggests that individuals exhibit an S-shaped utility (or value) function. Others have theorized that this may be due to the nature of preferences over losses and gains or the sensitivity of individuals to probabilities. It is possible that potential financial distress may be an important source of this Sshape in consumers' expected utility functions as well as firms' value functions, but that subject is outside the realm of our investigation. See Kahneman and Tversky (1979) and Friedman (1989).

${ }^{16}$ Strictly speaking, these conditions ensure only a local maximum. Risk aversion throughout the value function guarantees a unique global optimum, but in our model the convex portion of the value function leads to the theoretical possibility of local maximum in this region that is not a unique global maximum. Following Leland (1972) we will henceforth assume that the second order condition is satisfied for all output quantities $x$ and thus avoid the problem of local maxima.

17 The case of risk-seeking value maximization has been discussed by Leland (1972).

${ }^{18}$ If one assumes that the monopolistically competitive firm chooses price rather than quantity, the implications of uncertain demand and a non-linear value function are much more ambiguous. For a discussion of the issues involved, see Leland (1972).

19 Note, however, that Sandmo did not assume constant absolute risk aversion, and therefore in his model $U$ ''( $\Pi)$ is not assumed constant either, though its sign would always be negative.

20 Similarly, the nature of bankruptcy institutions for resolving distress will also affect the distribution of distress costs.

21 This is also the reason bankruptcy law treats transactions immediately prior to a bankruptcy filing with greater skepticism and may reverse decisions that appear to have been made contrary to the interests of all claimants.

${ }^{22}$ For example one might think of decisions by firms whether to undertake the development of a new product that would entail massive investment over many years, such as the development of a new aircraft, or even a new software application.

${ }^{23}$ Greenwald and Stiglitz (1971) mention the possibility of risk-seeking behavior, but only in passing in a footnote. Our model develops the full implications of risk-seeking behavior, and it shows that such behavior is likely to be chosen by many financially distressed firms. 


\section{Endnotes}

We thank William Neilson, John Huston, Barry Hirsch and seminar participants at Texas A\&M University for their comments and advice.

${ }^{1}$ For example, both customers and suppliers may for some time deal more warily with a once-distressed firm even though its current financial condition is sound - "once burned, twice shy."

${ }^{2}$ Note that since debts are unavoidable contractual costs, and the long run is conventionally defined as a period over which all costs are variable (avoidable), decisions taken over any period in which debts are owed are, by definition, short run decisions. One of the functions of the bankruptcy forum is to allow a firm to renegotiate, or abrogate, debt contracts. Thus bankruptcy makes some costs avoidable that were unavoidable outside this forum.

${ }^{3}$ While Greenwald \& Stiglitz motivate their model by focusing on managerial aversion to the possibility of bankruptcy (see p. 79 and footnote 5), they also address briefly how reorganization costs could be incorporated into that model (see footnote 12).

${ }^{4}$ Greenwald and Stiglitz do note in passing the possibility that firms could be risk-seeking rather than risk-averse when facing bankruptcy (see footnote 16), but they do not develop the implications of that case.

${ }^{5}$ See for example Jackson and Scott (1989), Daigle and Maloney (1994), and Meckling (1977).

${ }^{6}$ Since distress is the result of inadequate profits, even the distress costs that manifest themselves as changes in demand or input prices are best represented this way. The reason is that the magnitude of the change in the cost of inputs or demand is not exogenously determined but instead depends on the firm's profitability.

${ }^{7}$ The assets of an individual, especially her future earnings potential, are significantly protected from creditors under nearly all modern legal systems (e.g., we no longer imprison people for failure to pay their debts), whereas the assets of a firm may be liquidated entirely and all expected future profits, if such exist, destroyed.

${ }^{8}$ For further discussion of why it is appropriate to measure the value of the firm as the sum of debt and equity see Black and Scholes (1973) at p. 650.

${ }^{9}$ The full value of the firm to its creditors is bounded below at zero as well, but this point corresponds to a firm which has been completely dissolved (has no assets of any kind) so it is of little importance. In other words, a firm with any debt would be insolvent and distressed long before its value reached this lower bound.

${ }^{10}$ Note that the firm could not increase its value by simply borrowing money and buying liquid assets because the increase in liquidation value would be offset by a fall in the present value of expected future profits of equal or greater magnitude because the firm would face the cost of additional debt payments in the future.

${ }^{11}$ Though this example may seem rather contrived, it is in fact very similar to the assumptions made by other economists. Milne and Robertson (1996), for example, assume that if profits fall below a "tripwire" point the firm will be dissolved.

${ }^{12}$ A firm may have some costs that actually fall as profits fall and distress approaches. In particular, though we note above that distress may require that the firm pay a compensating wage differential due to employment uncertainty, distress may in other cases reduce labor costs. Consider heavily unionized settings, for example, where demands for 
wage increases are tied to firm profitability. Nevertheless, financial distress is certain to be a costly event for a firm on the whole.

${ }^{13}$ In our model only demand is assumed to be uncertain. However, one might readily conceive that distress costs (or other costs) might be uncertain as well, but adding these assumptions complicates the model without changing its implications.

${ }^{14} \mathrm{We}$ assume the default point is where the marginal distress cost associated with a decrease in profit peaks, which is why it corresponds to the mode of the distress cost distribution. If the default point were not associated with the mode of the distribution this would not fundamentally change the analysis.

${ }^{15}$ Interestingly, some empirical evidence suggests that individuals exhibit an S-shaped utility (or value) function. Others have theorized that this may be due to the nature of preferences over losses and gains or the sensitivity of individuals to probabilities. It is possible that potential financial distress may be an important source of this S-shape in consumers' expected utility functions as well as firms' value functions, but that subject is outside the realm of our investigation. See Kahneman and Tversky (1979) and Friedman (1989).

${ }^{16}$ Strictly speaking, these conditions ensure only a local maximum. Risk aversion throughout the value function guarantees a unique global optimum, but in our model the convex portion of the value function leads to the theoretical possibility of local maximum in this region that is not a unique global maximum. Following Leland (1972) we will henceforth assume that the second order condition is satisfied for all output quantities $x$ and thus avoid the problem of local maxima.

${ }^{17}$ The case of risk-seeking value maximization has been discussed by Leland (1972).

${ }^{18}$ If one assumes that the monopolistically competitive firm chooses price rather than quantity the implications of uncertain demand and a non-linear value function are much more ambiguous. For a discussion of the issues involved see Leland (1972).

${ }^{19}$ Note, however, that Sandmo did not assume constant absolute risk aversion, and therefore in his model $U^{\prime \prime}(\Pi)$ is not assumed constant either, though its sign would always be negative.

${ }^{20}$ Similarly, the nature of bankruptcy institutions for resolving distress will also affect the distribution of distress costs.

${ }^{21}$ This is also the reason bankruptcy law treats transactions immediately prior to a bankruptcy filing with greater skepticism and may reverse decisions that appear to have been made contrary to the interests of all claimants.

${ }^{22}$ For example one might think of decisions by firms whether to undertake the development of a new product that would entail massive investment over many years, such as the development of a new aircraft, or even a new software application.

${ }^{23}$ Greenwald and Stiglitz (1971) mention the possibility of risk-seeking behavior, but only in passing in a footnote. Our model develops the full implications of risk-seeking behavior, and it shows that such behavior is likely to be chosen by many financially distressed firms. 